\title{
Impact of Chemotherapy and Radiotherapy on the Survival of Elderly Esophagus Cancer Patients after Surgery: A SEER Database Analysis
}

\section{Xinrong Li}

The First Clinical College of Zhejiang Chinese Medical University

\section{Jin Zhang}

The First Clinical College of Zhejiang Chinese Medical University

\section{Junquan Zhu}

Department of Integrative Medicine \& Medical Oncology, Shengzhou People's Hospital (the First Affiliated Hospital of Zhejiang University Shengzhou Branch)

\section{Kaibo Guo}

The First Clinical College of Zhejiang Chinese Medical University

Yong Guo ( $\nabla$ guoyong1047@zcmu.edu.cn )

Department of Medical Oncology, The First Affiliated Hospital of Zhejiang Chinese Medical University

\section{Research Article}

Keywords: elderly patient, esophagus cancer, nomogram, predictive model, cancer specific death

Posted Date: January 14th, 2021

DOI: https://doi.org/10.21203/rs.3.rs-142330/v1

License: (a) (1) This work is licensed under a Creative Commons Attribution 4.0 International License. Read Full License 


\section{Abstract}

\section{Background}

Esophagus cancer (EC) is a common and lethal carcinoma, however, the effectiveness and feasibility of the conventional treatments for the elderly patients with surgery have not been discussed fully. The purpose of the current study is to discuss the potential effect of chemotherapy and radiotherapy on the prognosis.

\section{Results}

By PSM, chemotherapy (sHR: $0.588,95 \% \mathrm{Cl}: 0.453-0.763, \mathrm{P}<0.001$ ) and radiotherapy (sHR: $0.652,95 \% \mathrm{Cl}$ : $0.513-$ $0.83, P<0.001$ ) were showed a negative correlation to the probability of cancer specific death (CSD). Based on the nomogram, patients with poor differentiation, large tumor size, advanced T-staging, lymphatic metastasis and distant metastasis tended to benefit from chemotherapy (HR: $0.441,95 \% \mathrm{Cl}: 0.364-0.533, \mathrm{P}<0.001$ ) or radiotherapy (HR: $0.539,95 \% \mathrm{Cl}: 0.448-0.649, \mathrm{P}<0.001$ ) to decrease the probabilities of CSD, while no benefit or even harm was showed among the low-risk ones.

\section{Conclusion}

Aggressive treatment such as chemotherapy or radiotherapy was considered effective for the selective elder patients with EC.

\section{Introduction}

Esophagus cancer $(E C)$ is a common upper gastrointestinal tract carcinoma with high morbidity and mortality worldwide, with approximately $5.5 \%$ of new digestive tumor cases and $2.7 \%$ of tumor mortality in 2020.(1) And the incidence is believed to be increasing,(2) especially in some developing and deprived regions such as Eastern Asia as well as Southern and Eastern Africa.(3)

Recently, much progress referring the treatment has been made to improve the quality of life as well as to prolong the survival time, such as minimally invasive surgery for early-stage esophagus,(4) neoadjuvant chemotherapy for potentially respectable esophageal cancers histologically confirmed as squamous cell carcinoma (SCC)(5) or adenocarcinoma (AC)(6) at locally advanced stage as well as immune checkpoint inhibitor(7) for advanced EC. Despite this, owing to its extreme aggressive behaviors and the insensitiveness to the conventional treatment, the prognosis is still poor, accounting for $15-25 \%$ overall 5 -year survival rate worldwide.(2) Numerous studies(8-10) have indicated that old-age was a risk factor in reducing the survival probability of patients. Since the EC patients older than 70 years are not considered as candidates in regular clinical trials(11) for the decline of physiological function and the underlying comorbidities, the data concerning the management is limited and the principle of treatment remains unclear.(12) However, with the aging process of the global population, it is urgent to explore the roles of conventional treatments referring chemotherapy and radiotherapy in the old crowd with EC based on the existing data.

In this study, we analyzed the impact of chemotherapy and radiotherapy on the patients older than 70 years based on a large-scale population cohort from the SEER database. Firstly, we estimated the cumulative incidence function (CIF)(13) of chemotherapy and radiotherapy for the cancer specific death (CSD) based on 
the post-match cohorts respectively. Next, in order to overcome the possible selective bias caused by the propensity score matching (PSM),(14) a nomogram was established on the pre-match cohort to predict the risk score for every patient, who could be further labelled as high risk (high-score) or low risk (low-score) according to the median score of the whole crowds. Finally, predictive models were built to measure the effects of chemotherapy and radiotherapy in the specific old population.

\section{Materials And Methods Study Design}

Cases, histologically confirmed with EC according to the International Classification of Diseases in Oncology [ICD-0-3] ranging from 1998 to 2016, were identified from the Surveillance, Epidemiology, and End Results (SEER) database using the SEER ${ }^{\star S}$ tat Software (version 8.3.8). Since the 'SEER Combined Stage Group (2016+)' was derived from the cases ranging from 2004 to 2015, which were also classified by the TMN(6th ) staging-system, therefore, the above two staging standards could be combined to evaluate the disease. The tumor size was exactly determined by the record including 'EOD 10 - size (1988-2003)', 'CS tumor size (20042015)' or 'tumor Size Summary (2016+)' respectively, since measurement standards in the past 30 years were different. On the basis of data collation, a matrix could be built containing such information for race, age at diagnosis, marital status at diagnosis, anatomical region of EC, histological type and grade, TMN stagingsystem(6th), tumor size, treatment record (chemotherapy, radiotherapy and surgery), survival status, survival time and cause of death for every patient. Patients younger than 70y, with incomplete information, without surgery, or survival time shorter than 1 month were weeded out from the study.

\section{Statistical Analysis}

R-software packages of 'Matchlt' and 'cobalt' were used to conduct the PSM, packages of 'survival', 'cmprsk' and 'survminer' were used to establish competing risk models, packages of 'mstate', 'riskRegression' and 'rmda' were used to build nomogram, calibration curves and DCA curves. Categorical variables described as count and relative percentage, were compared by Chi-square test, and $\mathrm{P}<0.05$ was considered statistically significant.

With the inclusion and exclusion criterion mentioned above, the whole-population cohort was respectively divided into chemotherapy/non-chemotherapy groups and radiotherapy/non-radiotherapy groups through 1:1 nearest neighbor PSM with a caliper of 0.001 , then the sub-distribution hazard ratio (sHR) and hazard ratio (HR) were calculated to estimate the probabilities of cancer specific death (CSD) and overall survival (OS), and the results were presented by the CIF curves and Kaplan-Meier curves $(15,16)$, respectively. Love-plot(17) and $\chi 2$ test were further performed to assess the effectiveness of PSM. Furthermore, the whole-population cohort was randomized into training- and validation- sets at a ratio of 7:3. Based on the training set, univariate and multivariate competing risk models were established to select the independent risk factors for CSD. Next, highand low- risk groups could be derived from the training set according to the risk score which was calculated by the nomogram model built on the risk factors selected by the statistical calculation or clinical experience. After that, we could estimate the SHR for CSD and HR for OS in the above groups. Furthermore, both in the trainingand validation- sets, concordance indexes (C-index) were calculated to show the discrimination, and calibration curves were drawn to measure the consistency between the actual and expected value. Finally, decision curve 
analysis (DCA) was conducted to measure the superiorities of the nomogram model over the conventional TNM staging system.

\section{Results}

\section{Baseline Characteristics}

A total of 57503 cases were firstly downloaded from the SEER database (Fig. 1). Next, the initial cases were selected by the inclusion and exclusion criterion in the sequence as followed, the cases younger than 70y $(n=$ 35217), unknown race $(n=66)$, unknown marital status $(n=1093)$, unknown primary site $(n=2879)$, not SCC or AC histological type ( $n=1559)$, unknown differentiation grade $(n=2875)$, unknown T (tumor)-stage $(n=7565)$, unknown N(node) ( $n=296)$, unknown M (metastasis) $(n=57)$, unknown tumor size $(n=2023)$, unperformed surgery or unknown $(n=2611)$, unknown radiotherapy $(n=12)$, unknown cause of death $(n=5)$, survival time less than 1 month or unknown $(n=24)$ were excluded. Finally, 1221 eligible patients were left for the further analysis.

\section{Analysis in Post-Match Cohort}

Then, the 1221 cases were propensity matched according to the categorical variable of chemotherapy or radiotherapy respectively, as a result, 442 cases were divided into chemotherapy/non-chemotherapy cohort and 518 cases were divided into radiotherapy/non-radiotherapy cohort.

Before match, only the distributions of race $(P=0.342)$ in chemotherapy/non-chemotherapy cohort $($ Table 1$)$, gender $(P=0.128)$, race $(P=0.128)$, marital status $(P=0.066)$, tumor site $(P=0.865)$, tumor histological type ( $P$ $=0.819)$ and metastasis $(P=0.167)$ in radiotherapy/non-radiotherapy cohort were all similar $($ Table 2$)$. While, all the variates' distributions became balanced after match, indicating a good comparability between the groups with and without chemotherapy as well as radiotherapy. Furthermore, two love-plots were created to evaluate the effectiveness of PSM, plots distributed between the two dashed lines represented balance of corresponding variables (Supplementary Fig. 1A and 1B). 
Table 1

Clinical characteristics before and after PSM according to chemotherapy or not

\begin{tabular}{|c|c|c|c|c|c|c|}
\hline \multirow[t]{2}{*}{ Variables } & \multicolumn{2}{|l|}{ Before matching } & \multirow{2}{*}{$\begin{array}{l}\mathrm{Pa}^{\mathrm{a}} \\
\text { value }\end{array}$} & \multicolumn{2}{|l|}{ After matching } & \multirow{2}{*}{$\begin{array}{l}\mathrm{Pa}^{\mathrm{a}} \\
\text { value }\end{array}$} \\
\hline & $\begin{array}{l}\text { Chemotherapy } \\
n=622(\%)\end{array}$ & $\begin{array}{l}\text { Non- } \\
\text { chemotherapy } \\
n=599(\%)\end{array}$ & & $\begin{array}{l}\text { Chemotherapy } \\
n=221(\%)\end{array}$ & $\begin{array}{l}\text { Non- } \\
\text { chemotherapy } \\
n=221(\%)\end{array}$ & \\
\hline Gender & & & 0.004 & & & 0.897 \\
\hline Male & $522(83.92 \%)$ & $464(77.46 \%)$ & & 186(84.16\%) & 185(83.71\%) & \\
\hline Female & $100(16.08 \%)$ & $135(22.54 \%)$ & & $35(15.84 \%)$ & $36(16.29 \%)$ & \\
\hline Race & & & 0.342 & & & 1 \\
\hline White & $580(93.25 \%)$ & $550(91.82 \%)$ & & $214(96.83 \%)$ & $214(96.83 \%)$ & \\
\hline Other race ${ }^{b}$ & $42(6.75 \%)$ & $49(8.18 \%)$ & & $7(3.17 \%)$ & $7(3.17 \%)$ & \\
\hline Marriage & & & 0.001 & & & 0.92 \\
\hline Married & $453(72.83 \%)$ & $381(63.61 \%)$ & & $145(65.61 \%)$ & $146(66.06 \%)$ & \\
\hline Unmarried & $169(27.17 \%)$ & 218(36.39\%) & & $76(34.39 \%)$ & 75(33.94\%) & \\
\hline Site & & & 0.044 & & & 0.509 \\
\hline Upper third & $10(1.61 \%)$ & $16(2.67 \%)$ & & $5(2.26 \%)$ & $2(0.9 \%)$ & \\
\hline Middle third & $92(14.79 \%)$ & $115(19.2 \%)$ & & $22(9.95 \%)$ & $21(9.5 \%)$ & \\
\hline Low third & $520(83.6 \%)$ & 468(78.13\%) & & 194(87.78\%) & 198(89.59\%) & \\
\hline Histology & & & 0.026 & & & 0.704 \\
\hline SCC & 118(18.97\%) & $145(24.21 \%)$ & & $39(17.65 \%)$ & $36(16.29 \%)$ & \\
\hline Adenocarcinoma & $504(81.03 \%)$ & $454(75.79 \%)$ & & 182(82.35\%) & 185(83.71\%) & \\
\hline Grade $^{c}$ & & & 0.001 & & & 0.849 \\
\hline$\nabla+\otimes$ & $314(50.48 \%)$ & $357(59.6 \%)$ & & $103(46.61 \%)$ & $101(45.7 \%)$ & \\
\hline$\nabla+\nabla$ & $308(49.52 \%)$ & $242(40.4 \%)$ & & 118(53.39\%) & $120(54.3 \%)$ & \\
\hline Size & & & $\nabla 0.001$ & & & 0.923 \\
\hline$<35 \mathrm{~mm}$ & $217(34.89 \%)$ & $376(62.77 \%)$ & & $92(41.63 \%)$ & $91(41.18 \%)$ & \\
\hline$>=35 \mathrm{~mm}$ & $405(65.11 \%)$ & $223(37.23 \%)$ & & $129(58.37 \%)$ & $130(58.82 \%)$ & \\
\hline
\end{tabular}

a. The p-values of comparing chemotherapy and non-chemotherapy calculated with the use of a chi-square test;

b. Other race (Black/American Indian/AK Native, Asian/Pacific Islander);

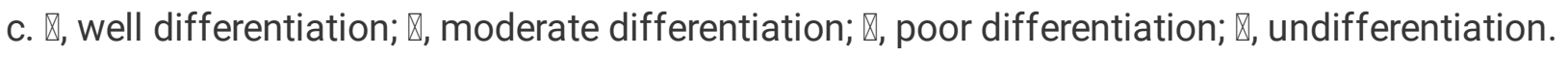




\begin{tabular}{|c|c|c|c|c|c|c|}
\hline \multirow[t]{2}{*}{ Variables } & \multicolumn{2}{|l|}{ Before matching } & \multirow{2}{*}{$\begin{array}{l}\mathrm{Pa}^{\mathrm{a}} \\
\text { value }\end{array}$} & \multicolumn{2}{|l|}{ After matching } & \multirow{2}{*}{$\begin{array}{l}\mathrm{P}^{\mathrm{a}} \\
\text { value }\end{array}$} \\
\hline & $\begin{array}{l}\text { Chemotherapy } \\
n=622(\%)\end{array}$ & $\begin{array}{l}\begin{array}{l}\text { Non- } \\
\text { chemotherapy }\end{array} \\
n=599(\%)\end{array}$ & & $\begin{array}{l}\text { Chemotherapy } \\
n=221(\%)\end{array}$ & $\begin{array}{l}\begin{array}{l}\text { Non- } \\
\text { chemotherapy }\end{array} \\
n=221(\%)\end{array}$ & \\
\hline T-stage & & & $\triangle 0.001$ & & & 1 \\
\hline T1 & 72(11.58\%) & $313(52.25 \%)$ & & $45(20.36 \%)$ & $45(20.36 \%)$ & \\
\hline T2 & 107(17.2\%) & $88(14.69 \%)$ & & $41(18.55 \%)$ & $41(18.55 \%)$ & \\
\hline T3 & $398(63.99 \%)$ & $180(30.05 \%)$ & & $128(57.92 \%)$ & $128(57.92 \%)$ & \\
\hline $\mathrm{T} 4$ & $45(7.23 \%)$ & 18(3.01\%) & & $7(3.17 \%)$ & $7(3.17 \%)$ & \\
\hline Lymph node & & & $\varangle 0.001$ & & & 0.924 \\
\hline positive & $425(68.33 \%)$ & $163(27.21 \%)$ & & $113(51.13 \%)$ & $112(50.68 \%)$ & \\
\hline negative & 197(31.67\%) & $436(72.79 \%)$ & & $108(48.87 \%)$ & $109(49.32 \%)$ & \\
\hline Metastasis & & & $\varangle 0.001$ & & & 0.793 \\
\hline Yes & $48(7.72 \%)$ & $21(3.51 \%)$ & & $8(3.62 \%)$ & $7(3.17 \%)$ & \\
\hline No & 574(92.28\%) & $578(96.49 \%)$ & & $213(96.38 \%)$ & $214(96.83 \%)$ & \\
\hline \multicolumn{7}{|c|}{$\begin{array}{l}\text { a. The p-values of comparing chemotherapy and non-chemotherapy calculated with the use of a chi-square } \\
\text { test; }\end{array}$} \\
\hline \multicolumn{7}{|c|}{ b. Other race (Black/American Indian/AK Native, Asian/Pacific Islander); } \\
\hline c. $\otimes$, well dit & $;$; & rer & & & lation. & \\
\hline
\end{tabular}


Table 2

Clinical characteristics before and after PSM according to radiotherapy or not

\begin{tabular}{|c|c|c|c|c|c|c|}
\hline \multirow[t]{2}{*}{ Variables } & \multicolumn{2}{|c|}{ Before matching } & \multirow{2}{*}{$\begin{array}{l}\mathrm{Pa}^{\mathrm{a}} \\
\text { value }\end{array}$} & \multicolumn{2}{|l|}{ After matching } & \multirow{2}{*}{$\begin{array}{l}\mathrm{P}^{\mathrm{a}} \\
\text { value }\end{array}$} \\
\hline & $\begin{array}{l}\text { Radiotherapy } \\
\mathrm{n}=574(\%)\end{array}$ & $\begin{array}{l}\text { Non- } \\
\text { radiotherapy } \\
n=647(\%)\end{array}$ & & $\begin{array}{l}\text { Radiotherapy } \\
\mathrm{n}=259(\%)\end{array}$ & $\begin{array}{l}\text { Non- } \\
\text { radiotherapy } \\
n=259(\%)\end{array}$ & \\
\hline Gender & & & 0.128 & & & 0.797 \\
\hline Male & $474(82.58 \%)$ & $512(79.13 \%)$ & & $225(86.87 \%)$ & $223(86.1 \%)$ & \\
\hline Female & $100(17.42 \%)$ & $135(20.87 \%)$ & & $34(13.13 \%)$ & $36(13.9 \%)$ & \\
\hline Race & & & 0.689 & & & 0.362 \\
\hline White & $533(92.86 \%)$ & $597(92.27 \%)$ & & $247(95.37 \%)$ & $251(96.91 \%)$ & \\
\hline Other race ${ }^{b}$ & $41(7.14 \%)$ & $50(7.73 \%)$ & & $12(4.63 \%)$ & $8(3.09 \%)$ & \\
\hline Marriage & & & 0.066 & & & 1 \\
\hline Married & 407(70.91\%) & $427(66 \%)$ & & $174(67.18 \%)$ & $174(67.18 \%)$ & \\
\hline Unmarried & $167(29.09 \%)$ & $220(34 \%)$ & & $85(32.82 \%)$ & $85(32.82 \%)$ & \\
\hline Site & & & 0.865 & & & 0.301 \\
\hline Upper third & $11(1.92 \%)$ & $15(2.32 \%)$ & & $3(1.16 \%)$ & $4(1.54 \%)$ & \\
\hline Middle third & $96(16.72 \%)$ & $111(17.16 \%)$ & & $29(11.2 \%)$ & 19(7.34\%) & \\
\hline Low third & 467(81.36\%) & $521(80.53 \%)$ & & $227(87.64 \%)$ & $236(91.12 \%)$ & \\
\hline Histology & & & 0.819 & & & 0.64 \\
\hline SCC & $122(21.25 \%)$ & $141(21.79 \%)$ & & $46(17.76 \%)$ & $42(16.22 \%)$ & \\
\hline ACC & 452(78.75\%) & $506(78.21 \%)$ & & 213(82.24\%) & $217(83.78 \%)$ & \\
\hline Grade $^{c}$ & & & 0.044 & & & 0.86 \\
\hline$\nabla+\square$ & 298(51.92\%) & $373(57.65 \%)$ & & $121(46.72 \%)$ & $123(47.49 \%)$ & \\
\hline$\nabla+\square$ & $276(48.08 \%)$ & $274(42.35 \%)$ & & 138(53.28\%) & $136(52.51 \%)$ & \\
\hline Size & & & $\otimes 0.001$ & & & 1 \\
\hline$<35 \mathrm{~mm}$ & $200(34.84 \%)$ & $393(60.74 \%)$ & & 103(39.77\%) & $103(39.77 \%)$ & \\
\hline$>=35 \mathrm{~mm}$ & $374(65.16 \%)$ & $254(39.26 \%)$ & & $156(60.23 \%)$ & $156(60.23 \%)$ & \\
\hline
\end{tabular}

a. The p-values of comparing chemotherapy and non-chemotherapy calculated with the use of a chi-square test;

b. Other race (Black/American Indian/AK Native, Asian/Pacific Islander);

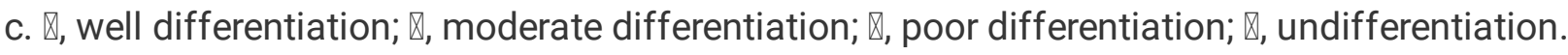




\begin{tabular}{|c|c|c|c|c|c|c|}
\hline \multirow[t]{2}{*}{ Variables } & \multicolumn{2}{|c|}{ Before matching } & \multirow{2}{*}{$\begin{array}{l}\mathrm{Pa}^{\mathrm{a}} \\
\text { value }\end{array}$} & \multicolumn{2}{|l|}{ After matching } & \multirow{2}{*}{$\begin{array}{l}\mathrm{P}^{\mathrm{a}} \\
\text { value }\end{array}$} \\
\hline & $\begin{array}{l}\text { Radiotherapy } \\
n=574(\%)\end{array}$ & $\begin{array}{l}\text { Non- } \\
\text { radiotherapy } \\
n=647(\%)\end{array}$ & & $\begin{array}{l}\text { Radiotherapy } \\
n=259(\%)\end{array}$ & $\begin{array}{l}\text { Non- } \\
\text { radiotherapy } \\
n=259(\%)\end{array}$ & \\
\hline T-stage & & & $\bowtie 0.001$ & & & 1 \\
\hline $\mathrm{T} 1$ & $65(11.32 \%)$ & $320(49.46 \%)$ & & $47(18.15 \%)$ & $47(18.15 \%)$ & \\
\hline T2 & $99(17.25 \%)$ & $96(14.84 \%)$ & & $48(18.53 \%)$ & $48(18.53 \%)$ & \\
\hline T3 & $368(64.11 \%)$ & $210(32.46 \%)$ & & $156(60.23 \%)$ & $156(60.23 \%)$ & \\
\hline T4 & $42(7.32 \%)$ & $21(3.25 \%)$ & & $8(3.09 \%)$ & $8(3.09 \%)$ & \\
\hline $\begin{array}{l}\text { Lymph } \\
\text { node }\end{array}$ & & & $\varangle 0.001$ & & & 1 \\
\hline positive & $385(67.07 \%)$ & 203(31.38\%) & & $145(55.98 \%)$ & $145(55.98 \%)$ & \\
\hline negative & 189(32.93\%) & $444(68.62 \%)$ & & 114(44.02\%) & 114(44.02\%) & \\
\hline Metastasis & & & 0.167 & & & 0.831 \\
\hline Yes & $38(6.62 \%)$ & $31(4.79 \%)$ & & $12(4.63 \%)$ & $11(4.25 \%)$ & \\
\hline No & $536(93.38 \%)$ & 616(95.21\%) & & 247(95.37\%) & 248(95.75\%) & \\
\hline \multicolumn{7}{|c|}{$\begin{array}{l}\text { a. The p-values of comparing chemotherapy and non-chemotherapy calculated with the use of a chi-square } \\
\text { test; }\end{array}$} \\
\hline \multicolumn{7}{|c|}{ b. Other race (Black/American Indian/AK Native, Asian/Pacific Islander); } \\
\hline ell $d$ & $n ; \bigotimes, m$ & te differen & boo & 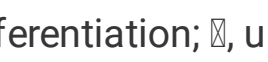 & fferentiatio & \\
\hline
\end{tabular}

After that, competing regression models were constructed to identify the chemotherapy (sHR: $0.588,95 \% \mathrm{Cl}$ : $0.453-0.763, \mathrm{P}<0.001$ ) and radiotherapy (sHR: $0.652,95 \% \mathrm{Cl}: 0.513-0.83, \mathrm{P}<0.001$ ) were both negatively correlated to the CSD (Fig. 2A-2B). As for the OS, Fig. 2C-2D showed the patients receiving chemotherapy (sHR: $0.631,95 \% \mathrm{Cl}: 0.498-0.8, \mathrm{P}<0.001$ ) or radiotherapy (sHR: $0.653,95 \% \mathrm{Cl}: 0.525-0.812, \mathrm{P}<0.001$ ) were less likely to have shorter survival.

\section{Analysis in Pre-Match Cohort}

In order to further study the effect of the chemotherapy and radiotherapy on the specific crowd in the population older than 70y, the 1221 cases were randomly divided into training- and validation- sets. In the training set, both univariate and multivariate analyses of competing risk models was performed to estimate probabilities of CSD, as a result, histological grade ('poorly or un-differentiation grade' vs 'well or moderate differentiation grade', sHR: $1.41,95 \% \mathrm{Cl}: 1.148-1.72$, P $<0.001$,), T-stage (T2 vs T1, sHR: $1.62,95 \% \mathrm{Cl}: 1.144-2.3$, $\mathrm{P}<0.007$; T3 vs T1, sHR: $2.31,95 \% \mathrm{Cl}: 1.677-3.19$, P<0.001; T4 vs T1, sHR: $3.36,95 \% \mathrm{Cl}: 1.964-5.76, \mathrm{P}<0.001)$ and lymph node (positive vs negative, sHR: $1.36,95 \% \mathrm{Cl}$ : 1.078-1.71, $\mathrm{P}<0.009$ ) were selected as the independent factors for the CSD (Table 3). 
Table 3

SHR of characteristics for CSD in univariate and multivariate competing risk models

\begin{tabular}{|c|c|c|c|c|c|c|}
\hline & Univari & e analysis & & Multiva & ate analysis & \\
\hline Characteristics & $\mathrm{sHR}^{\mathrm{a}}$ & $95 \% \mathrm{Cl}^{\mathrm{b}}$ & $P$ value & $\mathrm{sHR}^{\mathrm{a}}$ & $95 \% \mathrm{Cl}^{\mathrm{b}}$ & $P$ value \\
\hline Race & & & & & & \\
\hline White & 1(Ref) & & & & & \\
\hline Other race ${ }^{c}$ & 1.31 & $0.928-1.86$ & 0.12 & & & \\
\hline Gender & & & & & & \\
\hline Male & 1(Ref) & & & & & \\
\hline Female & 1.08 & $0.849-1.37$ & 0.54 & & & \\
\hline Marriage & & & & & & \\
\hline Unmarried & 1 (Ref) & & & & & \\
\hline Married & 0.945 & $0.765-1.17$ & 0.6 & & & \\
\hline Site & & & & & & \\
\hline Upper third & 1 (Ref) & & & & & \\
\hline Middle third & 0.913 & $0.485-1.72$ & 0.78 & & & \\
\hline Low third & 0.734 & $0.4-1.35$ & 0.32 & & & \\
\hline Histology & & & & & & \\
\hline Adenocarcinoma & 1(Ref) & & & & & \\
\hline SCC & 1.21 & $0.962-1.53$ & 0.1 & & & \\
\hline Grade $^{d}$ & & & & & & \\
\hline$\nabla+\mathbb{Q}$ & 1(Ref) & & & 1 (Ref) & & \\
\hline$\nabla+\mathbb{Q}$ & 1.73 & $1.42-2.1$ & $<0.001$ & 1.41 & $1.148-1.72$ & $<0.001$ \\
\hline Size & & & & & & \\
\hline$<35 \mathrm{~mm}$ & 1(Ref) & & & 1 (Ref) & & \\
\hline$>=35 \mathrm{~mm}$ & 1.79 & $1.47-2.19$ & $<0.001$ & 1.12 & $0.898-1.4$ & 0.31 \\
\hline T-stage & & & & & & \\
\hline a. sHR, sub-distrib & on haza & I ratio; & & & & \\
\hline b. $\mathrm{Cl}$, confidence in & rval; & & & & & \\
\hline c. Other race (Blac & America & Indian/AK Nat & e, Asian/P & cific Isla & der); & \\
\hline d. $\otimes$, well differen & $n ; \otimes, r$ & ra & 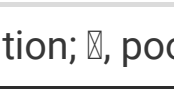 & & & \\
\hline
\end{tabular}




\begin{tabular}{|c|c|c|c|c|c|c|}
\hline & \multicolumn{3}{|c|}{ Univariate analysis } & \multicolumn{3}{|c|}{ Multivariate analysis } \\
\hline $\mathrm{T} 1$ & 1 (Ref) & & & 1 (Ref) & & \\
\hline T2 & 1.96 & $1.42-2.71$ & $<0.001$ & 1.62 & $1.144-2.3$ & 0.007 \\
\hline T3 & 3.13 & $2.4-4.09$ & $<0.001$ & 2.31 & $1.677-3.19$ & $<0.001$ \\
\hline T4 & 5.2 & $3.34-8.1$ & $<0.001$ & 3.36 & $1.964-5.76$ & $<0.001$ \\
\hline \multicolumn{7}{|c|}{ Lymph node } \\
\hline Negative & \multicolumn{3}{|c|}{1 (Ref) } & \multicolumn{3}{|c|}{ 1(Ref) } \\
\hline Positive & 2.15 & $1.76-2.63$ & $<0.001$ & 1.36 & $1.078-1.71$ & 0.009 \\
\hline \multicolumn{7}{|c|}{ Metastasis } \\
\hline No & \multicolumn{3}{|c|}{ 1(Ref) } & \multicolumn{3}{|l|}{ 1(Ref) } \\
\hline Yes & 1.86 & $1.3-2.67$ & $<0.001$ & 1.33 & $0.89-2$ & 0.16 \\
\hline \multicolumn{7}{|c|}{ a. sHR, sub-distribution hazard ratio; } \\
\hline \multicolumn{7}{|c|}{ b. Cl, confidence interval; } \\
\hline \multicolumn{7}{|c|}{ c. Other race (Black/American Indian/AK Native, Asian/Pacific Islander); } \\
\hline d. $\otimes$, well & $n ; \otimes, n$ & roto diffor & $n n^{n}$ & & & \\
\hline
\end{tabular}

With consideration of the above statistical results, previously published articles or clinical experiences, a nomogram was established based on the variates including tumor precise location, histological grade, tumor size, T-stage, lymphatic and distant metastasis with the purpose of prediction possibilities of CSD in the next 1-, 3- and 5-year (Fig. 3). The c-indexes for the competing risk regression model were 0.634 in the training set and 0.666 in the validation set. As Fig. 4 showed, the 1-, 3-, 5- year predictive probabilities of CSD derived from the nomogram model were matched well to the actual ones both in the training- (Fig. 4A, Fig. 4C, Fig. 4E) and validation- (Fig. 4B, Fig. 4D, Fig. 4F) sets. Furthermore, the DCA curves were established by nomogram model and conventional TNM staging-system for estimating the 1- (Fig. 5A), 3- (Fig. 5B), 5- (Fig. 5C) year net benefits of CSD, reflecting a superiority of nomogram model over the TNM model for predicting the survival outcomes. On the basis of risk score for each case derived from the nomogram, the 1221 patients could be separated into high- $(n=619)$ and low- risk $(n=602)$ crowds by the median score of 92 (high risk: score > = 92; low risk: score< 92). Next, the competing regression model was performed to show that the old patients from the high-risk group were more likely to benefit from the chemotherapy (Fig. $6 \mathrm{~A}$, sHR:0.512, $95 \% \mathrm{Cl}: 0.413-0.635, \mathrm{P}<0.001$ ) and radiotherapy (Fig. 6B, sHR:0.601, 95\%Cl: $0.49-0.736, \mathrm{P}<0.001$ ) for the lower probabilities of CSD, while neither chemotherapy (Fig. 6C, sHR:1.01, 95\% Cl: $0.736-1.38, \mathrm{P}=0.96$ ) nor radiotherapy (Fig. 6D, sHR:1.19, 95\%Cl: $0.868-1.63, P=0.28$ ) could affect the incidence of CSD for the low-risk population. Furthermore, the risk classification for patients based on the CSD prediction model of nomogram was further used to measure the OS outcomes, as Fig. 7 showed, the high-risk patients with chemotherapy (Fig. 7A, HR: 0.441, 95\%Cl: 0.364$0.533, \mathrm{P}<0.001$ ) or radiotherapy (Fig. 7B, HR: $0.539,95 \% \mathrm{Cl}: 0.448-0.649, \mathrm{P}<0.001$ ) tended to have lower probabilities of death comparing the ones without it. However, the results were not consistent in the low-risk group, no significantly different possibilities of survival (Fig. 7C, chemotherapy vs non-chemotherapy, HR: 
1.024, 95\%Cl: $0.793-1.322, \mathrm{P}=0.855)$ or even worse survival outcomes (Fig. 7D, radiotherapy vs nonradiotherapy, $\mathrm{HR}: 1.307,95 \% \mathrm{Cl}: 1.014-1.684, \mathrm{P}=0.039)$ was observed among the low-risk population.

\section{Discussion}

With the extension of life expectancy, more ES patients would present in their ages over 60 years old.(18) A Chinese study indicated an increased incidence and mortality was observed among the patients older than 70 years comparing to other age stratifications,(19) leading to a sharp increase health care costs in both the developing(20) and developed(21) countries. However, the guidelines that specifically address the management of the older EC patient are rare, only a few studies referring the topics of evaluation and treatment for the elderly.

In the present study, based on the cohorts after PSM, we found that both chemotherapy and radiotherapy could present a positive impact on CSD and OS of the elderly patients. Then, the univariate and multivariate competing regression model were performed to identify lower grade, advanced T-stage and positive lymph node status were significantly correlated to the higher probabilities of CSD. Besides, the tumor size and distant metastasis were also considered as the key factors to predict the prognosis of EC. Kamel et.al. pointed out the size of malignancy $(H R=1.005)$ was a significantly independent predictor to the CSD for the T1N0M0 patients based on the SEER database.(22) Malnutritional status were correlated with poor survival,(23) while the tumor size of esophagus was significantly correlated to nutritional status measured by prognostic nutritional index ( $p$ = 0.016).(24) Furthermore, larger tumor size was a predictive factor to identify the EC patients who might have a higher rate of resection with the help of neoadjuvant therapy.(25) When it came to the tumor site, the different anatomical locations of EC was usually correlated to the variable treatment responses as well as survival outcome. The upper third was commonly associated with the poor prognosis, but tended to be more sensitivity to the chemo-radiotherapy.(26) Finally, after reviewing 838 patients with EC between 1982 and 1993, Quint indicated metastases were commonly diagnosed in lymph nodes, liver, lung, bone, adrenal, etc., determining the further management and predicting prognosis.(27)

By the variables mentioned above, a nomogram could be established to estimate the risk score for every patient, then the high- and low- risk (score) groups could be derived from whole-population cohort. With a series of analysis, both the chemotherapy and radiotherapy were showed to decrease the probabilities of CSD as well as improve the survival in the high-risk group, indicating elderly patients with the disease characterized as middle- \& upper- third of tumor location, poorly- \& un-differentiated of histological grade, >=35 mm of tumor size, advanced T-stage, positive lymph node and (or) metastasis tend to benefit from the relative aggressive treatment. However, in the low-risk group, no significant benefits for CSD were observed in the elderly population neither receiving chemotherapy nor radiotherapy. Furthermore, by performing the log-rank test, a significantly negative impact of radiotherapy was observed on the OS, suggesting providing aggressive therapies for the old characterized as low-third of tumor location, well- \& moderate-differentiated of histological grade, $<35 \mathrm{~mm}$ of tumor size, early T-stage, negative lymph node and (or) non-metastasis was unfavorable. The above result was concordance with the current studies as follows.

As for the chemotherapy, the OE0-2 trial conducted by Medical Research Council of the U.K showed, receiving regimens of cisplatin and 5 -FU before surgery $(n=86)$ could prolong the survival of patients $(>75 y)$ with a HR of 0.7 , compared to the ones receiving surgery alone $(n=79) .(28)$ Besides, a randomized trial from Germany 
indicated that, compared to the double combinations of 5-fluorouracil, leucovorin and oxaliplatin (FLO) a triple combination of 5-fluorouracil, leucovorin, oxaliplatin and docetaxel (FLOT) could improve therapeutic response and progression-free survival in the patients aged from 65 to 70 years, which was associated with higher incidence of side effects for diarrhea $(P=0.006)$, alopecia $(P<0.001)$, neutropenia $(P<0.001)$, nausea $(P=$ $0.029)$ and leukopenia $(P<0.001) .(29)$ When it comes to the radiotherapy, the CROSS trail found that chemoradiotherapy followed surgery was more favorable for patients with a median age of $60 \mathrm{y}$, compared to the surgery alone.(30) The median OS was 48.6 months versus 24.0 months (HR: 0.68, $P=0.003$ ), respectively. However, a multi-center randomized phase III trial of FFCD 9901 containing 195 patients with a median age of approximately 60 years old to study the effect of neoadjuvant chemoradiotherapy on the ones with early stage $\mathrm{EC}$, as a result, no significant positive impact on rate of $\mathrm{RO}$ resection or survival prognosis was observed, but the mortality after surgery was increased.(31)

Generally speaking, it was widely accepted that both the chemotherapy and radiotherapy could exert a positive effect on the survival of elderly EC patients. For instance, after reviewing 21593 EC patients aged 70 years or older from the National Cancer Database, Gregory et.al pointed out any cancer-related treatment could play a positive role to prolong the survival of the old EC patient.(32) Similarly, Daniela et.al used SEER Database(2001-2009) to show that an improved 5-year survival could be observed in the elder patients $(\geq 65 y)$ receiving any medical or surgical therapy.(33) But, the possible defect in these studies was that the authors did not use competitive risk model to avoid the interference of non-cancer specific death on the survival analysis. Furthermore, with consideration of the balance between benefits and harms referring therapies in the old population, it was vital to identify the specific crowd tended to benefit or be suffered from the anti-tumor treatment, which was usually absent in most current studies.

There were some limitations in our studies. Firstly, it was a retrospective research based on the SEER only covering $30 \%$ population of the US,(34) with poor representation of the variable incidence and prognosis of EC worldwide.(35) Secondly, the qualified cases involved in our study was not enough to develop a strong nomogram model with considerable net benefit. Thirdly, some important information such as the life of quality, complications and treatment protocols were absent in the SEER database, therefore, the further analysis of certain specific subgroup could not be performed. Last, due to the lack of specific time-point for treatment, a clear causal relationship between treatment and prognosis could not be showed.

\section{Conclusions}

Based on the post-match cohorts by PSM, we found chemotherapy and radiotherapy could decrease the probabilities of CSD and improve OS in the EC patients (> 70y) in general. While the further analysis of subcohort marked as the high- and low- risk groups by a nomogram indicated that the high-risk patients characterized as middle- \& upper- third of tumor location, poorly- \& un-differentiated of histological grade, >=35 mm of tumor size, advanced T-stage, positive lymph node and (or) metastasis could be considered as benefited crowd for the aggressive anti-tumor treatment. However, for the low-risk people characterized as lowthird of tumor location, well- \& moderate-differentiated of histological grade, $<35 \mathrm{~mm}$ of tumor size, early Tstage, negative lymph node and (or) non-metastasis, both the chemotherapy and radiotherapy could not bring therapeutic benefits or even exert a negative effect on the survival outcomes. Despite of this, well-designed trails are still needed to validate our conclusions based on the real-world clinical practice.

Page 12/23 


\section{Declarations}

\section{DATA AVAILABILITY STATEMENT}

The data that support the findings of this study are available from the corresponding author upon reasonable request.

\section{ACKNOWLEDGEMENTS}

Not applicable.

\section{FUNDING SUPPORT}

Sponsored by Zhejiang Provincial Project for the key discipline of traditional Chinese Medicine (Yong Guo, NO. 2017-XK-A09, http://www.zjwjw.gov.cn/)

\section{CONFLICT OF INTEREST DISCLOSURES}

The authors declare that the research was conducted in the absence of any commercial or financial relationships that could be construed as a potential conflict of interest.

\section{CONSENT FOR PUBLICATION}

Not applicable.

\section{AUTHOR CONTRIBUTIONS}

Xinrong Li: Conceptualization, formal analysis, interpretation, writing-original draft and writing-critical revision. Yong Guo: Conceptualization, methodology, writing-critical revision, resource provision and supervision. Jin Zhang: Methodology, data analysis and interpretation. Kaibo Guo: Figures and tables editing.

Ethics approval and consent to participatE

This study was approved by the Institutional Ethical Committee of Shengzhou People's Hospital, and the requirement for informed consent was waived.

\section{References}

1. Siegel RL, Miller KD. Cancer statistics, 2020. 2020;70:7-30.

2. Pennathur A, Gibson MK, Jobe BA, et al. Oesophageal carcinoma. Lancet 2013;381:400-12.

3. Ferlay J, Soerjomataram I, Dikshit R, et al. Cancer incidence and mortality worldwide: sources, methods and major patterns in GLOBOCAN 2012. Int J Cancer 2015;136:E359-86.

4. Muto M, Minashi K, Nihei K, et al. Efficacy of combined endoscopic resection and chemoradiotherapy for clinical stage I esophageal squamous cell carcinoma (ESCC): A single-arm confirmatory study (JCOG0508). Journal of Clinical Oncology 2016;34:4013-. 
5. Ando $\mathrm{N}$, Kato $\mathrm{H}$, Igaki $\mathrm{H}$, et al. A randomized trial comparing postoperative adjuvant chemotherapy with cisplatin and 5-fluorouracil versus preoperative chemotherapy for localized advanced squamous cell carcinoma of the thoracic esophagus (JCOG9907). Ann Surg Oncol 2012;19:68-74.

6. Cunningham D, Allum WH, Stenning SP, et al. Perioperative chemotherapy versus surgery alone for resectable gastroesophageal cancer. N Engl J Med 2006;355:11-20.

7. Kojima T, Muro K, Francois E, et al. Pembrolizumab versus chemotherapy as second-line therapy for advanced esophageal cancer: Phase III KEYNOTE-181 study. Journal of Clinical Oncology 2019;37:2-.

8. Zarean E, Mahmoudi M, Azimi T, et al. Determining Overall Survival and Risk Factors in Esophageal Cancer Using Censored Quantile Regression. Asian Pac J Cancer Prev 2018;19:3081-6.

9. Lu PP, Zhang N, Ma HM, et al. [Study on the related factors of esophageal cancer and precancerous lesions in rural residents aged 40-69 years in Shandong Province]. Zhonghua Yu Fang Yi Xue Za Zhi 2019;53:1104-9.

10. Asombang AW, Chishinga N, Nkhoma A, et al. Systematic review and meta-analysis of esophageal cancer in Africa: Epidemiology, risk factors, management and outcomes. World J Gastroenterol 2019;25:4512-33.

11. Servagi-Vernat S, Créhange G, Bonnetain F, et al. Chemoradiation in elderly esophageal cancer patients: rationale and design of a phase I/II multicenter study (OSAGE). BMC Cancer 2017;17:483.

12. Won E. Issues in the management of esophageal cancer and geriatric patients. Chin Clin Oncol 2017;6:51.

13. Kim HT. Cumulative incidence in competing risks data and competing risks regression analysis. Clin Cancer Res 2007;13:559-65.

14. Duhamel A, Labreuche J, Gronnier C, et al. Statistical Tools for Propensity Score Matching. Ann Surg 2017;265:E79-e80.

15. Gray RJ. A Class of K-Sample Tests for Comparing the Cumulative Incidence of a Competing Risk. The Annals of Statistics 1988;16:1141-54.

16. Lim HJ, Zhang X, Dyck R, et al. Methods of competing risks analysis of end-stage renal disease and mortality among people with diabetes. BMC Med Res Methodol 2010;10:97.

17. Zhang Z, Kim HJ, Lonjon G, et al. Balance diagnostics after propensity score matching. Ann Transl Med 2019;7:16.

18. Bollschweiler E, Plum P, Mönig SP, et al. Current and future treatment options for esophageal cancer in the elderly. Expert Opin Pharmacother 2017;18:1001-10.

19. Fan J, Liu Z, Mao X. Global trends in the incidence and mortality of esophageal cancer from 1990 to 2017. 2020:e03338.

20. Collaborators. GOC. The global, regional, and national burden of oesophageal cancer and its attributable risk factors in 195 countries and territories, 1990-2017: a systematic analysis for the Global Burden of Disease Study 2017. Lancet Gastroenterol Hepatol 2020;5:582-97.

21. Arnold M, Laversanne M, Brown LM, et al. Predicting the Future Burden of Esophageal Cancer by Histological Subtype: International Trends in Incidence up to 2030. Am J Gastroenterol 2017;112:1247-55.

22. Kamel MK, Lee B, Rahouma M, et al. T1N0 oesophageal cancer: patterns of care and outcomes over 25 years. Eur J Cardiothorac Surg 2018;53:952-9. 
23. Sakai M, Sohda M, Miyazaki T, et al. Association of Preoperative Nutritional Status with Prognosis in Patients with Esophageal Cancer Undergoing Salvage Esophagectomy. Anticancer Res 2018;38:933-8.

24. Zhang $H$, Shang $X$, Ren $P$, et al. The predictive value of a preoperative systemic immune-inflammation index and prognostic nutritional index in patients with esophageal squamous cell carcinoma. 2019;234:1794802.

25. Kidane B, Korst RJ, Weksler B, et al. Neoadjuvant Therapy Vs Upfront Surgery for Clinical T2N0 Esophageal Cancer: A Systematic Review. Ann Thorac Surg 2019;108:935-44.

26. Papp A, Cseke L, Farkas R, et al. Chemo-radiotherapy in locally advanced squamous cell oesophageal cancer-are upper third tumours more responsive? Pathol Oncol Res 2010;16:193-200.

27. Lagergren J, Smyth E, Cunningham D, et al. Oesophageal cancer. Lancet 2017;390:2383-96.

28. Group. MRCOCW. Surgical resection with or without preoperative chemotherapy in oesophageal cancer: a randomised controlled trial. Lancet 2002;359:1727-33.

29. Al-Batran SE, Pauligk C, Homann N, et al. The feasibility of triple-drug chemotherapy combination in older adult patients with oesophagogastric cancer: a randomised trial of the Arbeitsgemeinschaft Internistische Onkologie (FLOT65+). Eur J Cancer 2013;49:835-42.

30. Shapiro J, van Lanschot JJB, Hulshof M, et al. Neoadjuvant chemoradiotherapy plus surgery versus surgery alone for oesophageal or junctional cancer (CROSS): long-term results of a randomised controlled trial. Lancet Oncol 2015;16:1090-8.

31. Mariette C, Dahan L, Mornex F, et al. Surgery alone versus chemoradiotherapy followed by surgery for stage I and II esophageal cancer: final analysis of randomized controlled phase III trial FFCD 9901. J Clin Oncol 2014;32:2416-22.

32. Vlacich G, Samson PP, Perkins SM, et al. Treatment utilization and outcomes in elderly patients with locally advanced esophageal carcinoma: a review of the National Cancer Database. Cancer Med 2017;6:2886-96.

33. Molena D, Stem M, Blackford AL, et al. Esophageal Cancer Treatment Is Underutilized Among Elderly Patients in the USA. J Gastrointest Surg 2017;21:126-36.

34. Hayat MJ, Howlader N, Reichman ME, et al. Cancer statistics, trends, and multiple primary cancer analyses from the Surveillance, Epidemiology, and End Results (SEER) Program. Oncologist 2007;12:20-37.

35. Malhotra GK, Yanala U, Ravipati A, et al. Global trends in esophageal cancer. 2017;115:564-79.

\section{Figures}




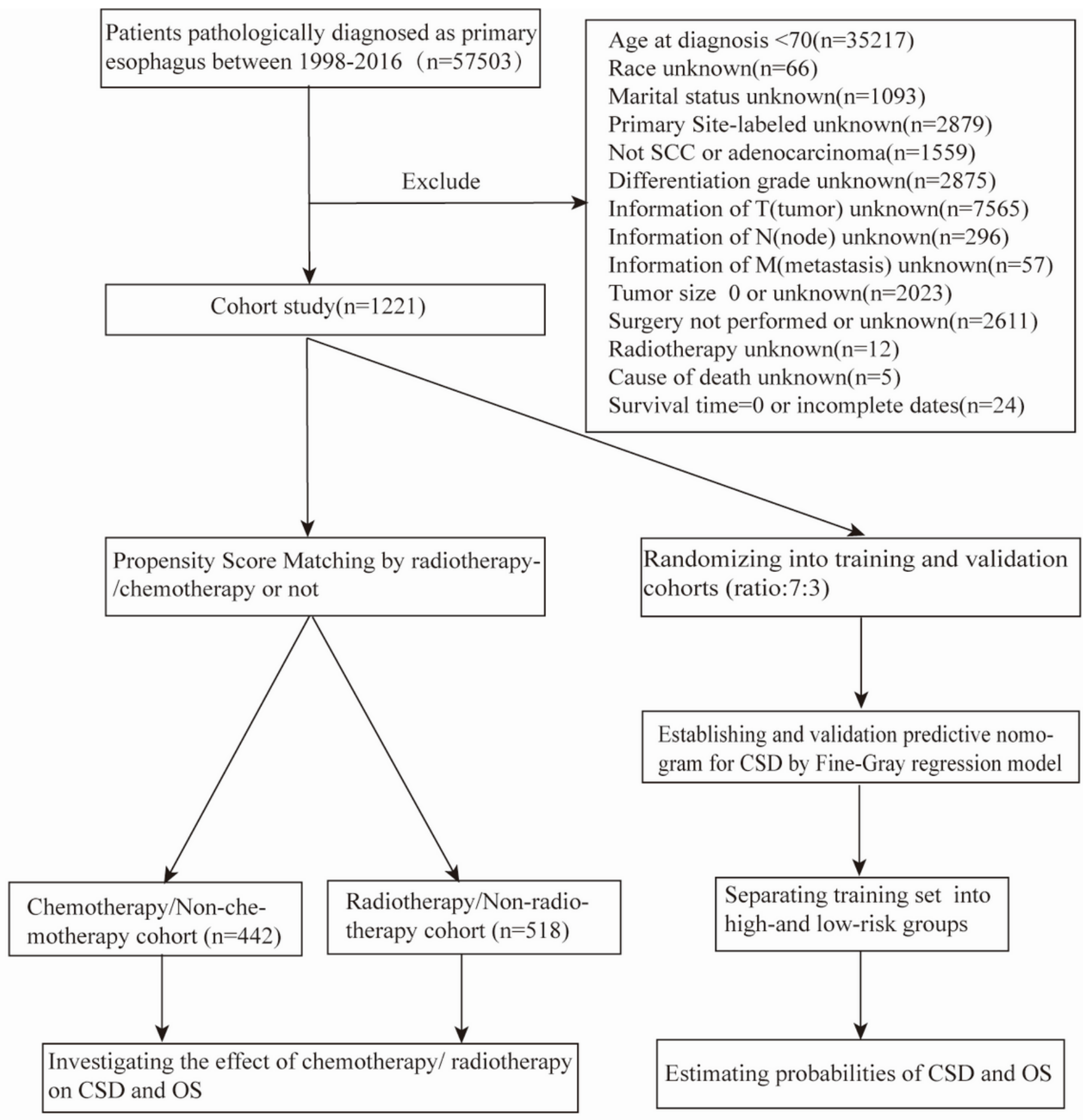

\section{Figure 1}

The data selection steps of the present study. 
A
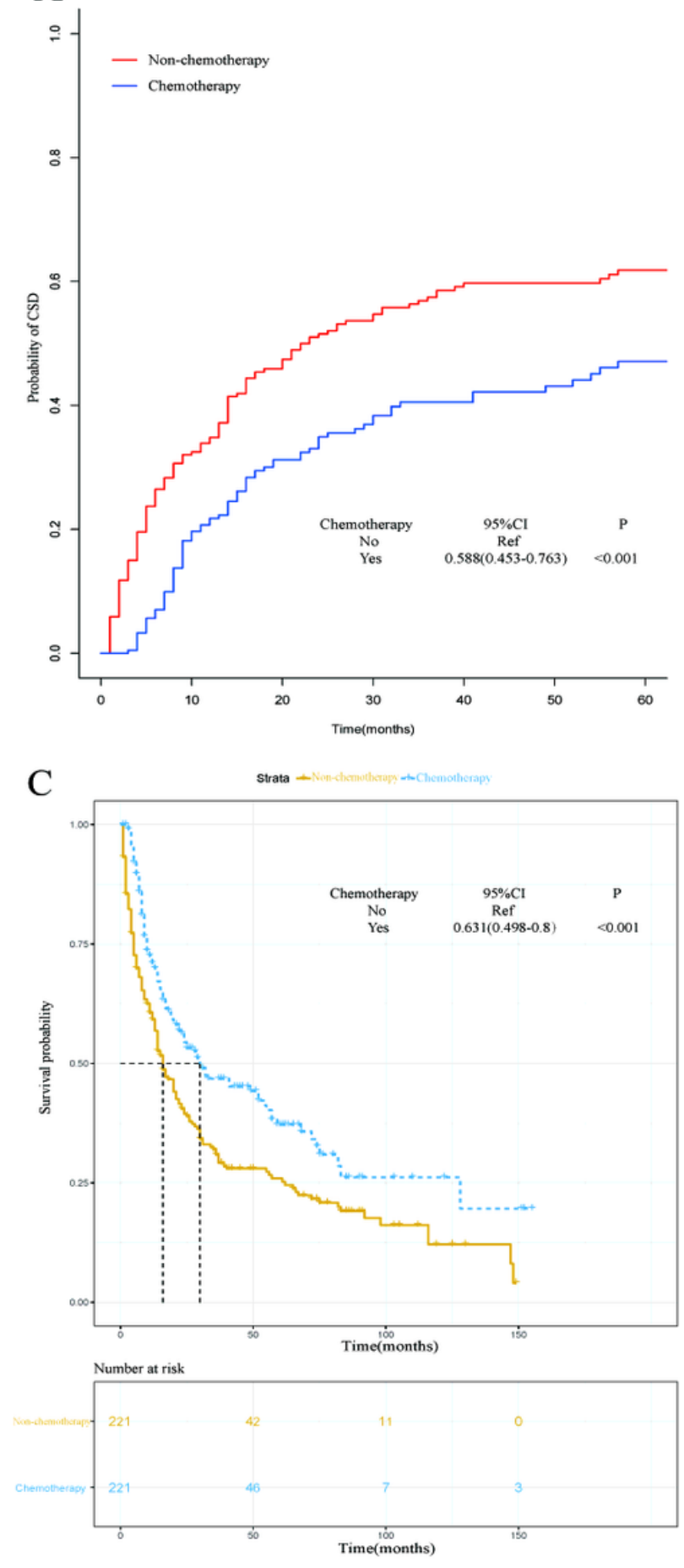

\section{B}

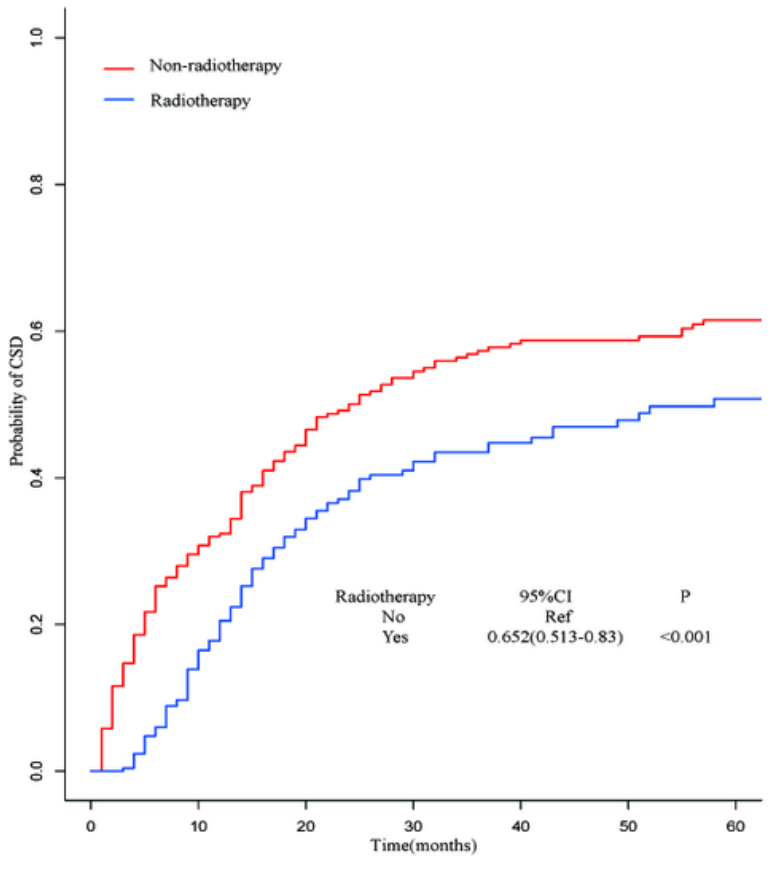

$\mathrm{D}$
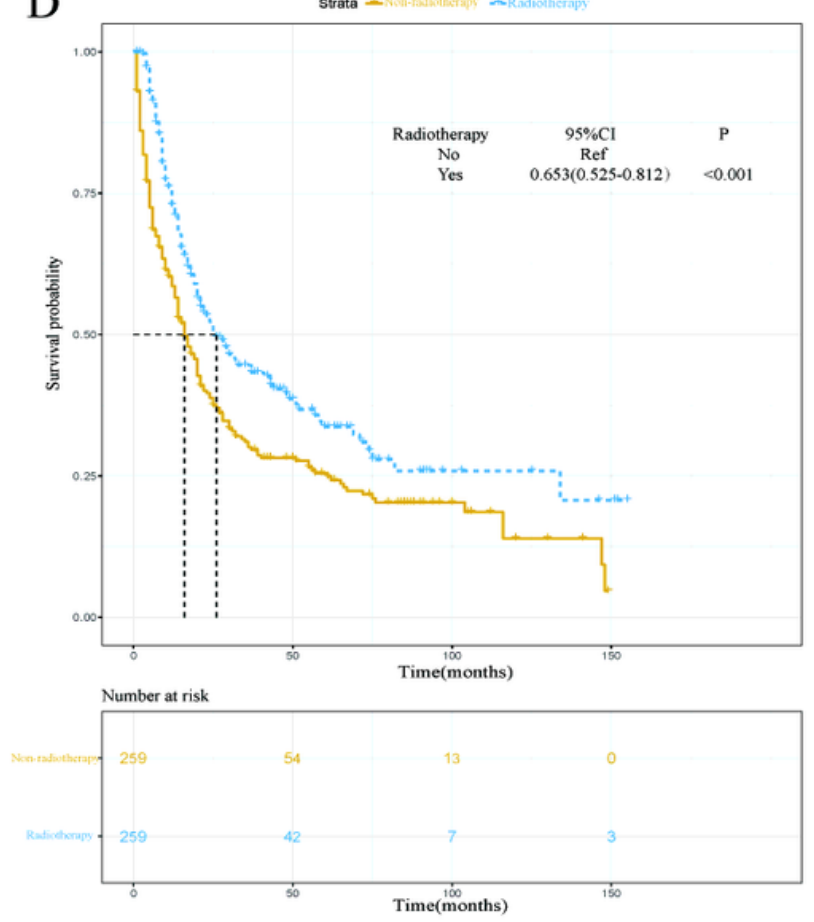

Figure 2

A. Cumulative incidence estimates of CSD for patients with or without chemotherapy in the post-match cohort;

B. Cumulative incidence estimates of CSD for patients with or without radiotherapy in the post-match cohort; C Overall survival of the post-match population with or without chemotherapy; D Overall survival of the postmatch population with or without radiotherapy. 
Points

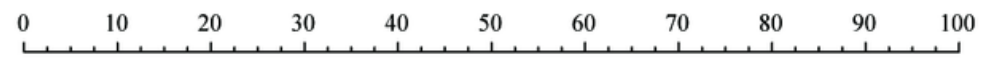

Site

Size

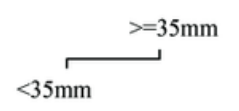

T-stage

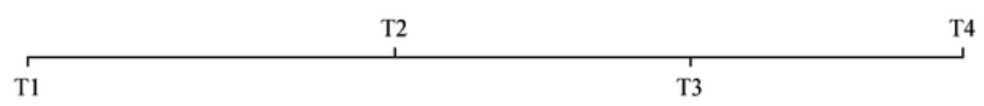

Lymph node

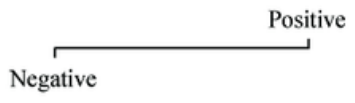

Metastasis

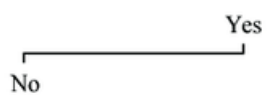

Total Points

\begin{tabular}{lllllllllllll}
\hline 0 & 20 & 40 & 60 & 80 & 100 & 120 & 140 & 160 & 180 & 200 & 220 & 240
\end{tabular}

1-year Probability of CSD

\begin{tabular}{llllllllllll}
\hline 0.1 & 0.15 & 0.2 & 0.25 & 0.3 & 0.35 & 0.4 & 0.45 & 0.5 & 0.55 & 0.6 & 0.65
\end{tabular}

3-year Probability of CSD

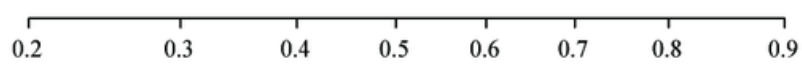

5-year Probability of CSD

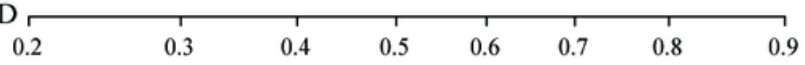

\section{Figure 3}

Nomogram predicting 1-, 3-, and 5-year probabilities of CSD for EC patients based on the training cohort. 

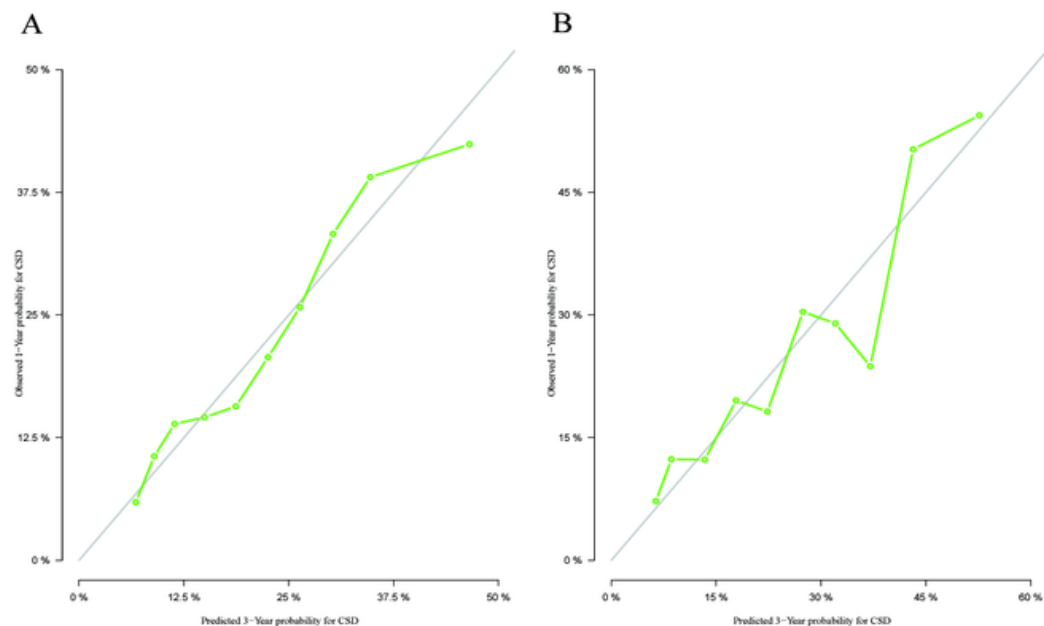

$\mathrm{D}$

$\mathrm{C}$
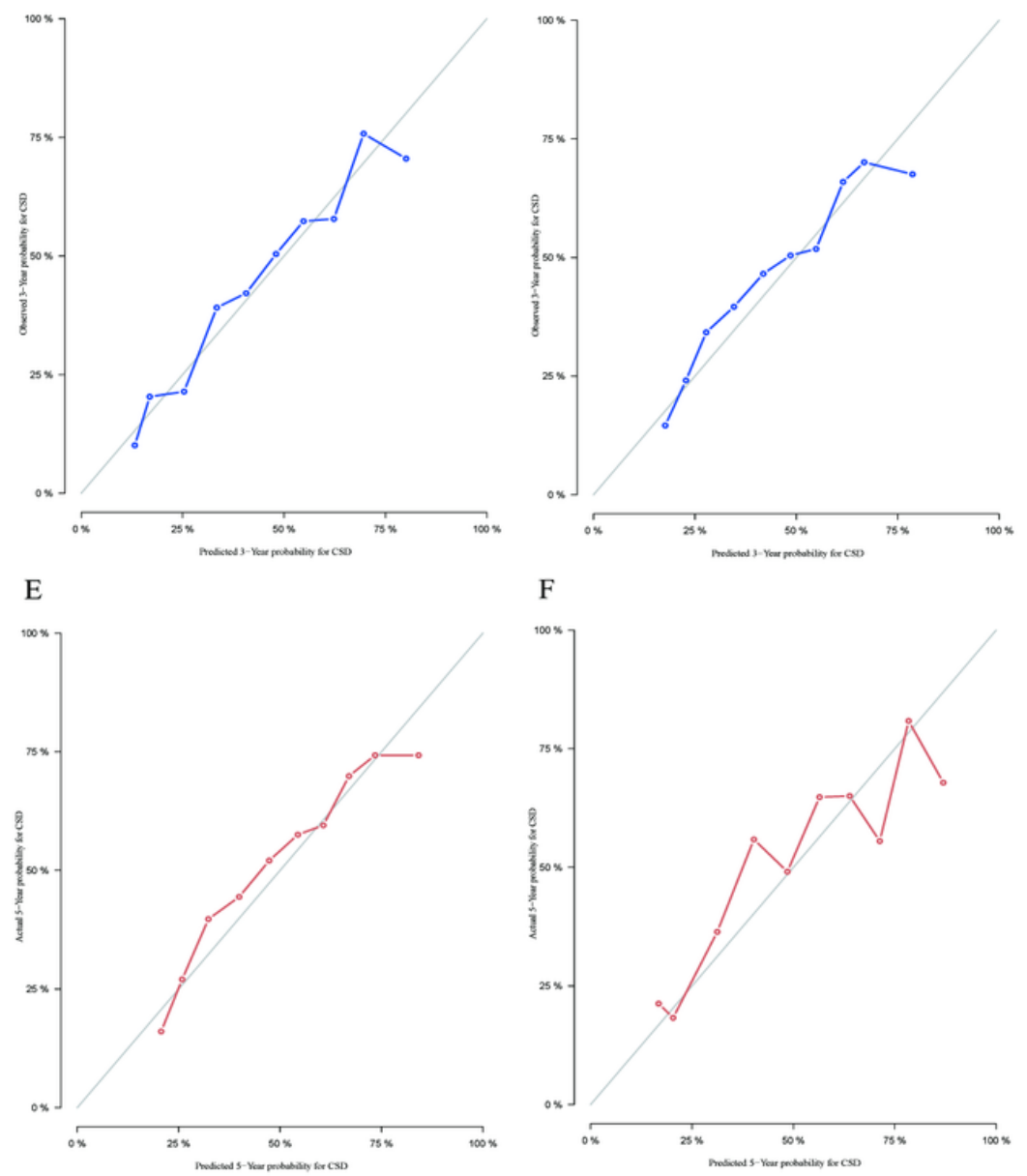

Figure 4

(A, C, E) The calibration curves of nomogram for predicting 1-, 3-, and 5-year probabilities of CSD in the training set. $(B, D, F)$ The calibration curves of nomogram for predicting 1-, 3-, and 5-year probabilities of CSD in the validation set. Nomogram-predicted CSD is plotted on the $x$-axis; actual CSD is plotted on the $y$-axis. The imaginary line indicates a perfect calibration model in which the predicted probabilities are identical to the actual incidence. 
A

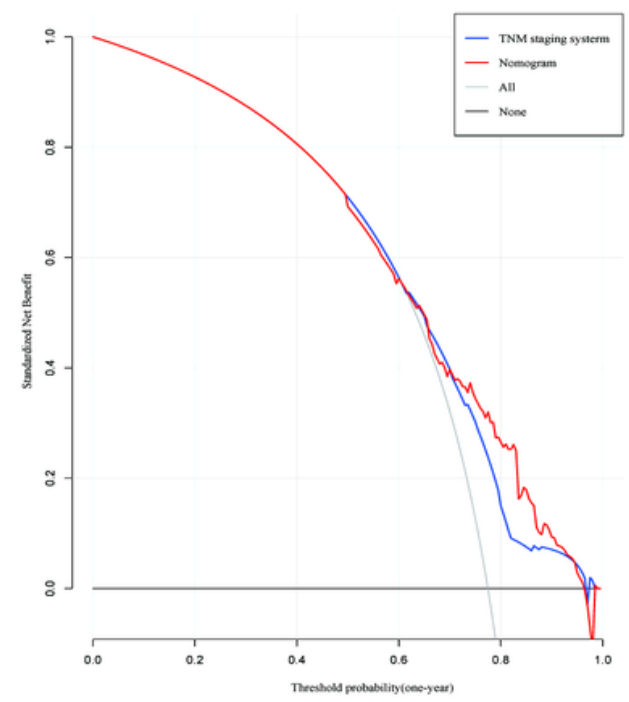

B

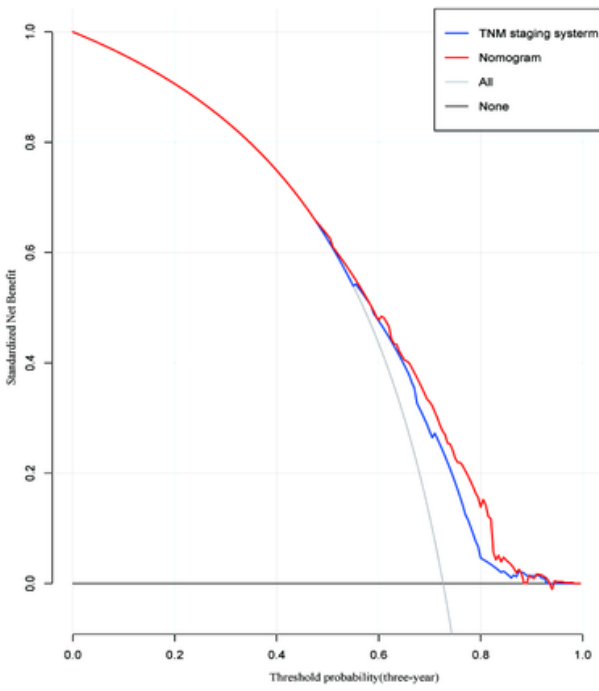

$\mathrm{C}$
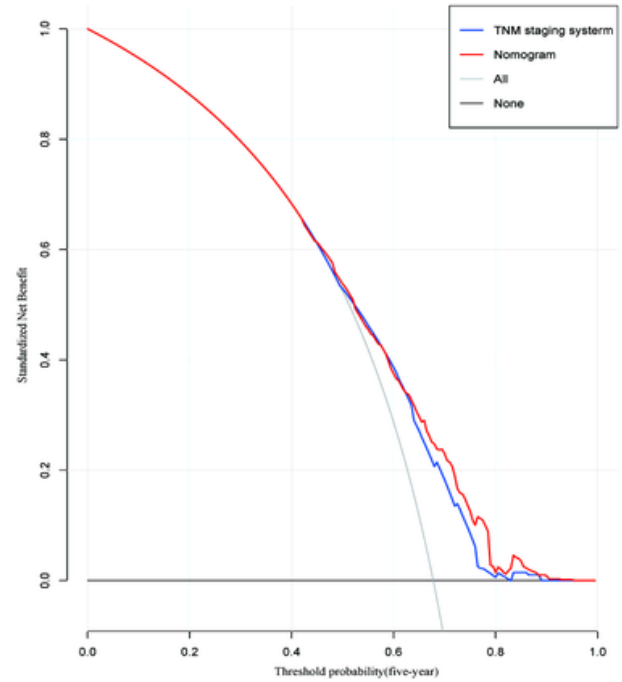

Figure 5

Decision curve analysis (DCA) of the nomogram and 6th edition AJCC TNM staging system for 1-year (A), 3year (B), and 5-year (C) overall survival. The $x$-axis measures the threshold probabilities, and the $y$-axis represents the net benefit. The horizontal line along the $x$-axis assumes that overall death occurred in no patients, while the solid gray line assumes that all patients will have overall death at a specific threshold probability. The blue solid line represents 6th edition AJCC TNM staging system. The red solid line represents the nomogram. 
A

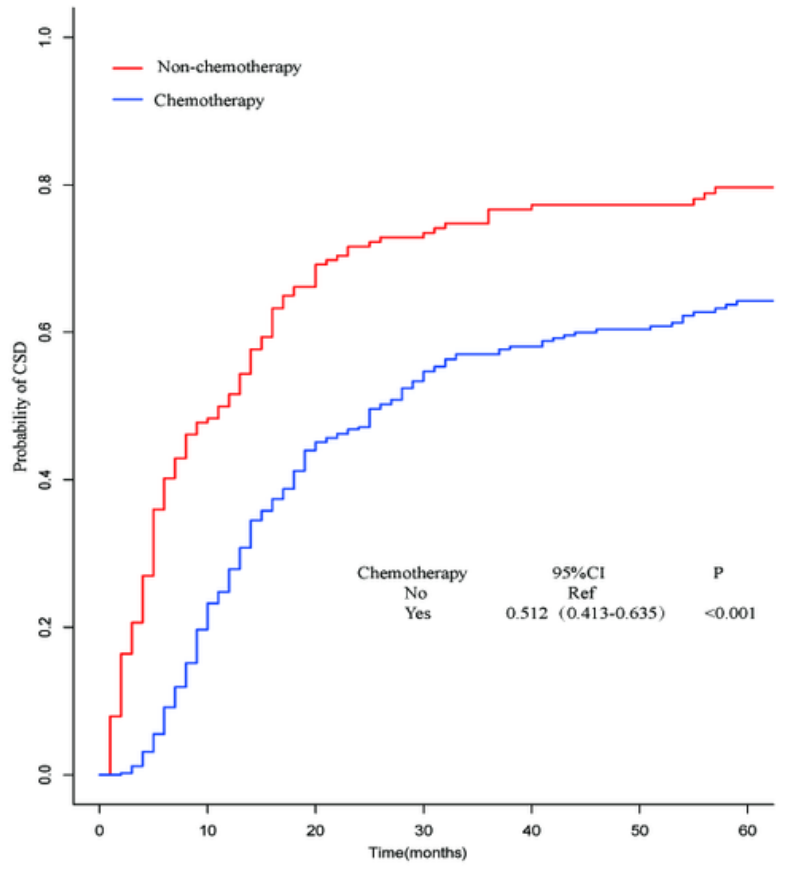

C

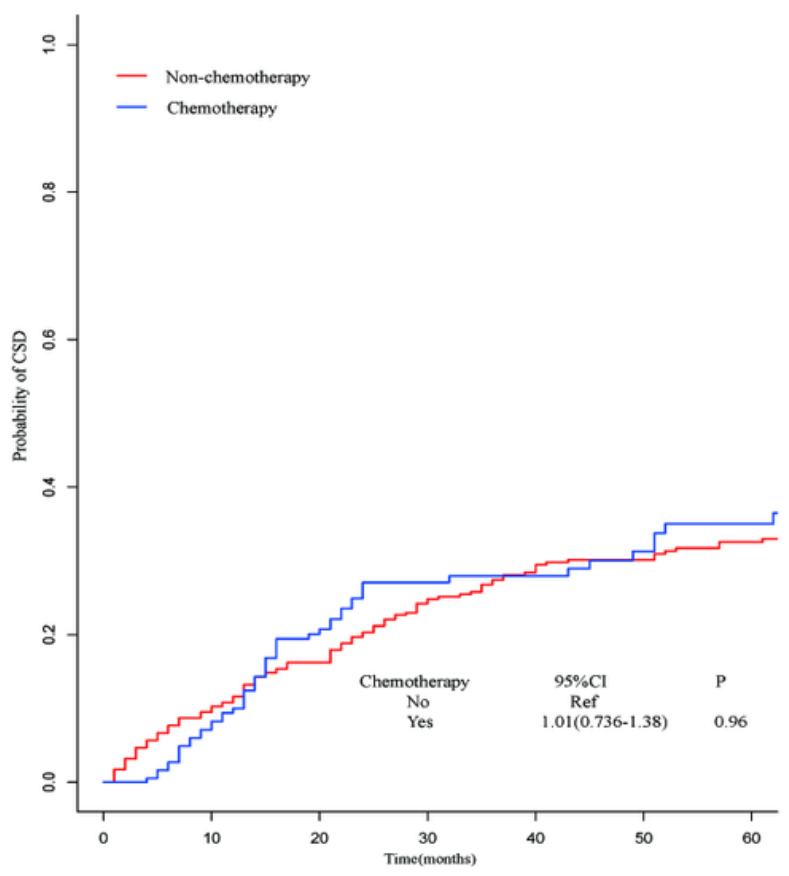

B

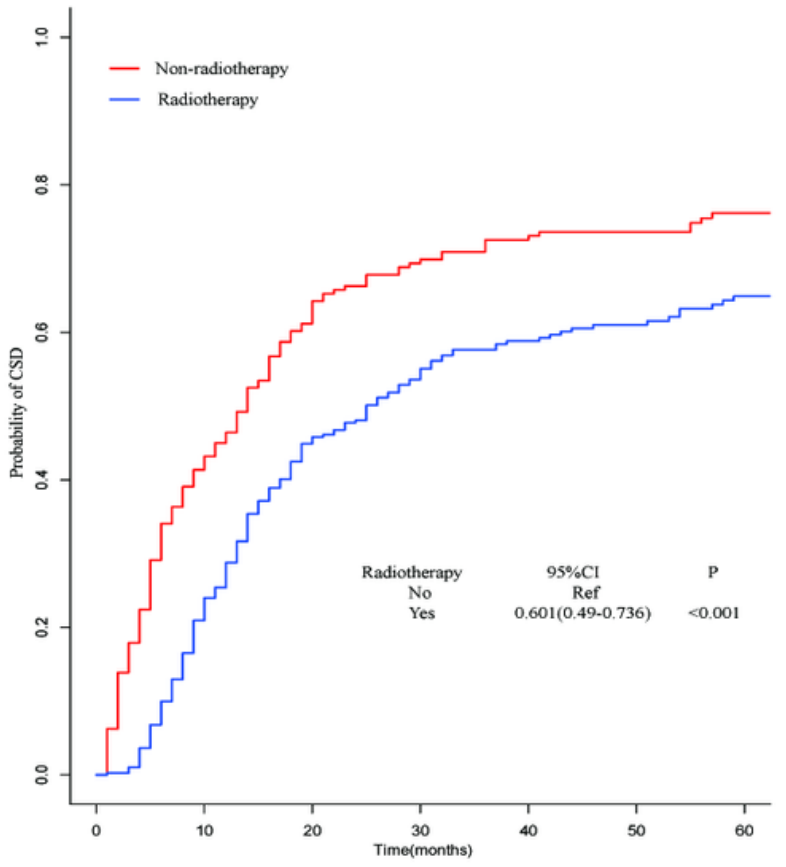

$\mathrm{D}$

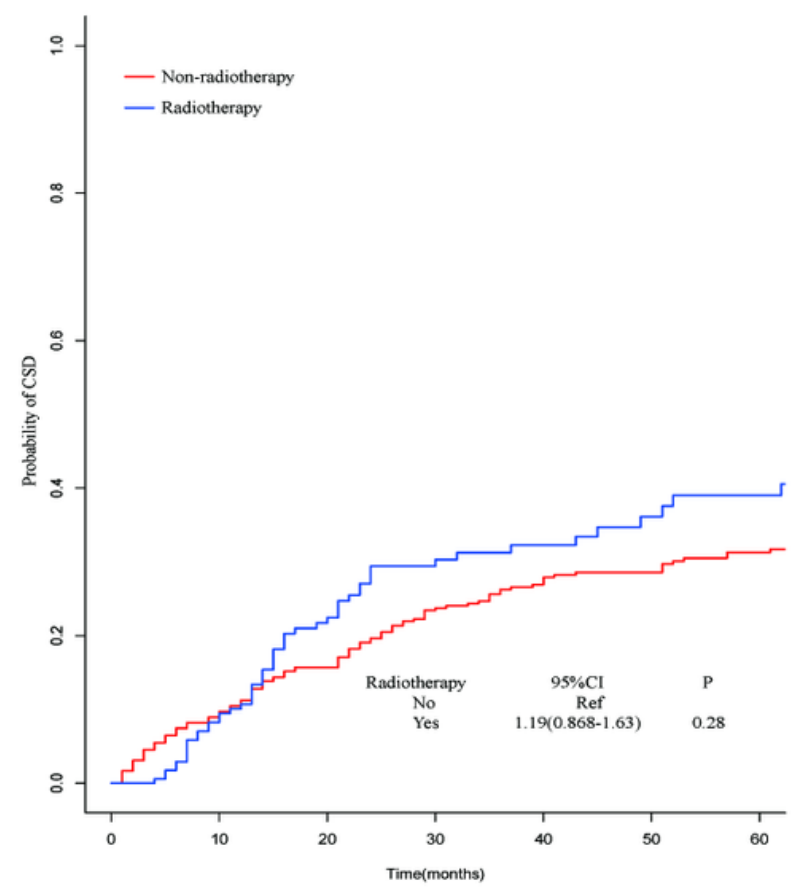

Figure 6

A. Cumulative incidence estimates of CSD for EC patients with or without chemotherapy in the high-risk group;

B. Cumulative incidence estimates of CSD for EC patients with or without radiotherapy in the high-risk group; C. Cumulative incidence estimates of CSD for EC patients with or without chemotherapy in the low-risk group; D. Cumulative incidence estimates of CSD for EC patients with or without radiotherapy in the low-risk group. 
A
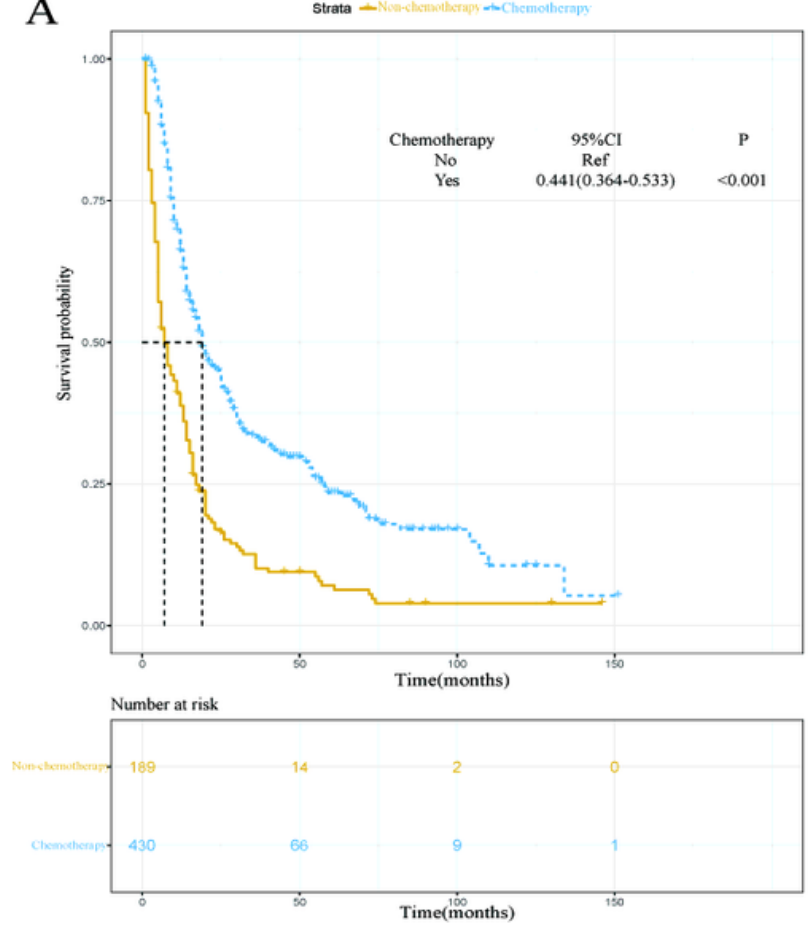

C
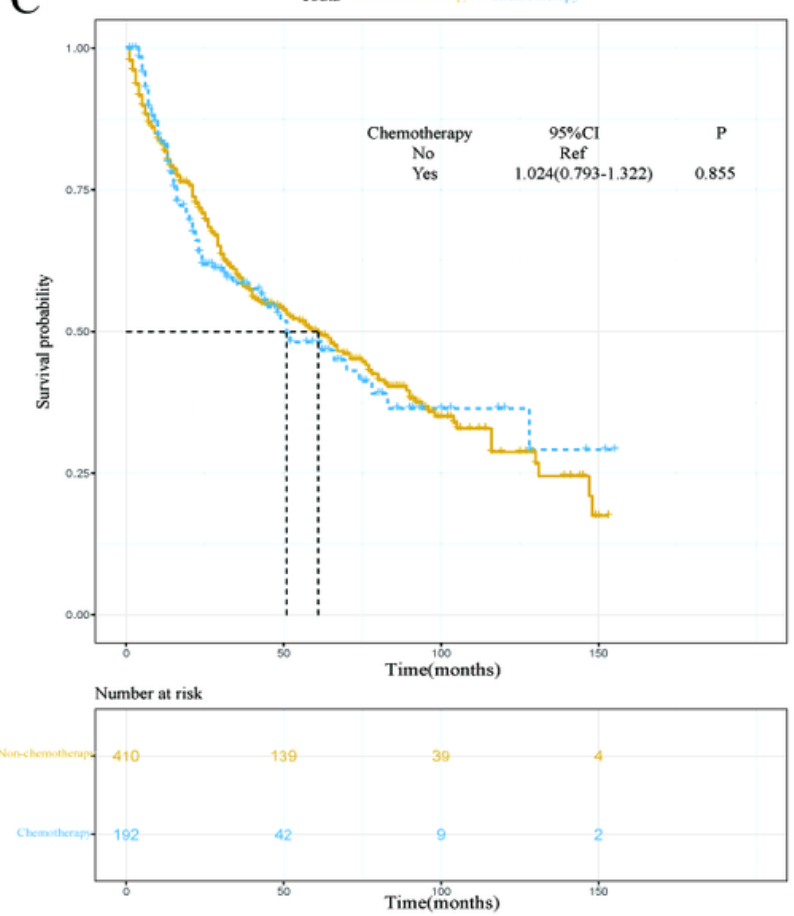

B
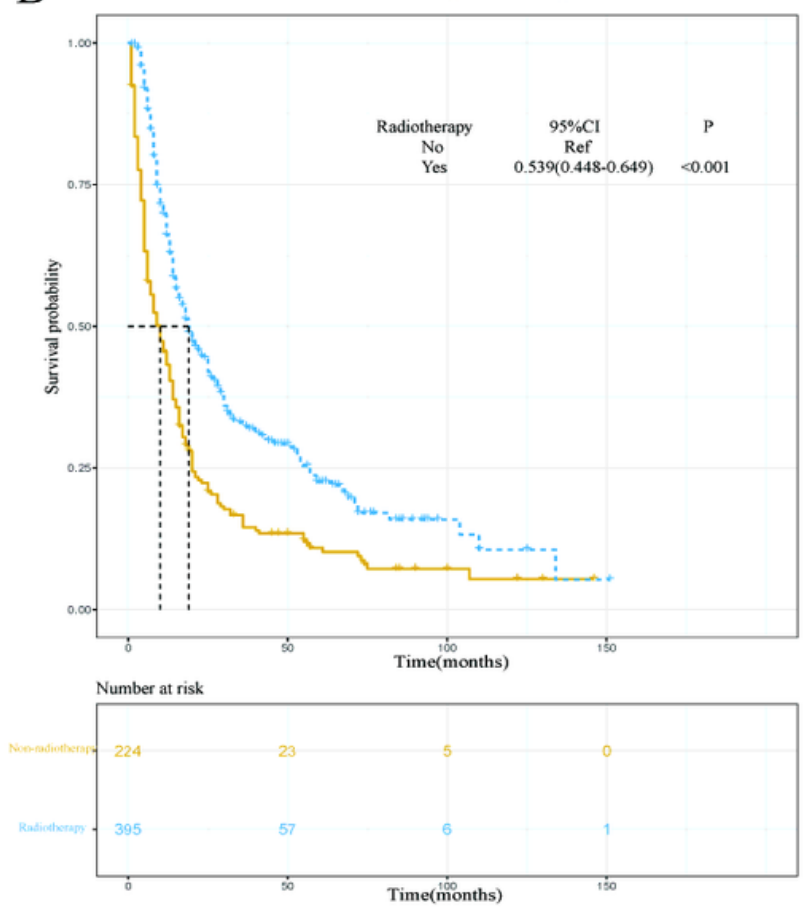

D
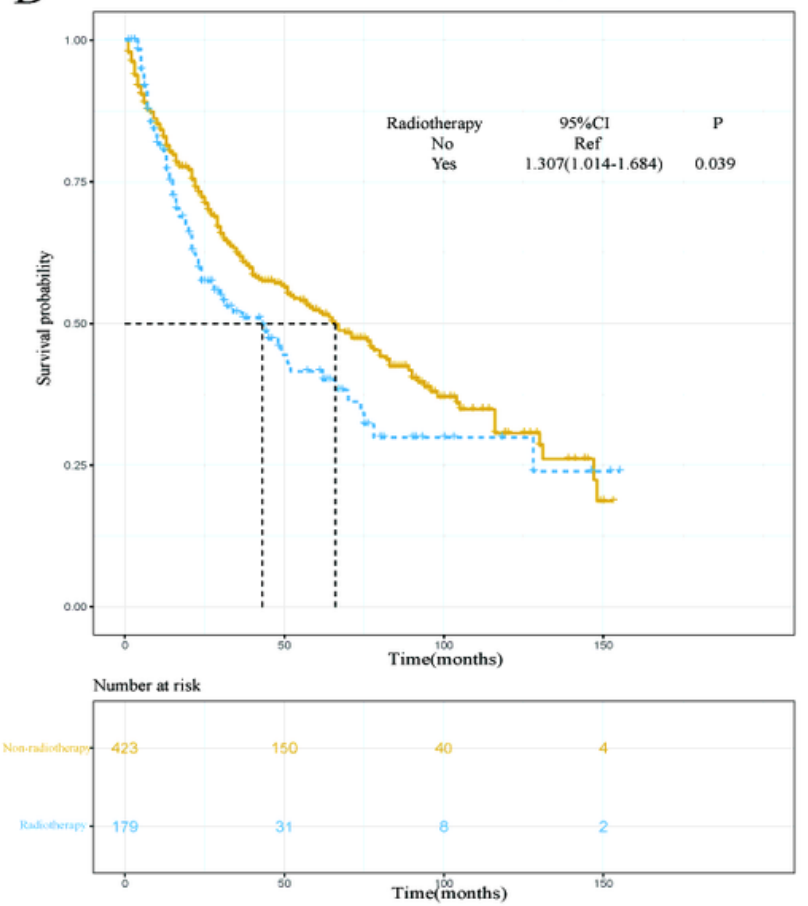

Figure 7

A. Overall survival of EC patients with or without chemotherapy in the high-risk group; B. Overall survival of EC patients with or without radiotherapy in the high-risk group; C. Overall survival of EC patients with or without chemotherapy in the low-risk group; D. Overall survival of EC patients with or without radiotherapy in the lowrisk group.

\section{Supplementary Files}


This is a list of supplementary files associated with this preprint. Click to download.

- SupplementaryFigure1.tif 